\title{
Canguilhem e o caráter filosófico das ciências da vida*
}

\section{| ${ }^{1}$ Dina Czeresnia |}

Resumo: Este artigo aborda a importância do pensamento de Canguilhem para transformaçooes nas ciências da vida e também da relação entre ciência e filosofia. Afirma que o conceito de normatividade vital, ao propor valor como uma característica essencial da vida, aponta um problema fundamental do conhecimento biológico. Este conceito é central no pensamento de Canguilhem e acompanha toda a sua obra, como confirma a Conferência sobre Cérebro e Pensamento, realizada em 1980. Sua atualidade é atestada na discussão de questôes em aberto nas neurociências e na definição de vida. Não há uma definição de vida que seja curta, universal e igualmente aceita como definição padrão entre as ciências. A definição de vida como posição inconsciente de valor não se coaduna com a perspectiva quantitativa das ciências da natureza. O que poderia ser valor como definição do que é vida? Constituintes metabólicos poderiam apresentar uma dimensão que se considera inaugurada pela vida humana? Para equacionar essas interrogações, seriam necessárias mudanças na concepção do que é o homem e da sua relação com o conhecimento. Finalmente, é apresentada a afinidade entre o conceito de normatividade vital e o de vontade de poder, de Nietzsche. O conceito de normatividade vital encontra o de vontade de poder como uma potência que realiza a própria vida orgânica. Considerar que valor é anterior ao homem é afirmar a realidade biológica do pensamento, da qual o humano é um desdobramento que realiza o sentido da própria experiência vital.

> Palavras-chave: Canguilhem, ciências da vida, filosofia.
1 Doutora em Saúde Pública, Pesquisadora da Escola Nacional de Saúde Pública - FIOCRUZ e CNPq. Endereço eletrônico: dina@ensp.fiocruz.br

Recebido em: 02/03/2010 Aprovado em: 26/05/2010

\footnotetext{
* Texto elaborado no contexto da pesquisa de pós-doutorado realizada no Instituto de Filosofia e Ciências Sociais - IFICS/ UFRJ, sob orientação do professor Emmanuel Carneiro Leão
} 


\section{Introdução}

O objetivo deste artigo é compreender o conceito de normatividade vital de Georges Canguilhem (1904-1995) como crucial a um melhor entendimento da relação entre ciência e filosofia. Defende-se que o conceito de normatividade vital, ao apontar um problema fundamental do conhecimento biológico, indica a necessidade de uma transformação dessa relação e, consequentemente, da própria ciência da vida.

Os problemas relativos ao conhecimento biológico estão vinculados a importantes questôes dos modelos de assistência à saúde. Do ponto de vista epistemológico, a grande interrogação é a dualidade que separa corpo e mente; psíquico e somático, e que não corresponde à experiência concreta da saúde e da doença. Do ponto de vista das práticas de saúde, essa dualidade se reflete na persistência de um modelo técnico que também dissocia assistência e realidades sociais, culturais e afetivas. Predomina a perspectiva que favorece intervençóes tecnológicas avançadas, mas pobres do ponto de vista afetivo.

Questiona-se a racionalidade e sustentabilidade desse modelo. $\mathrm{O}$ discurso da promoção da saúde propõe, de diferentes formas e perspectivas, a inversão das prioridades e investimentos em saúde. Porém, por mais que a lógica orientadora da organização sanitária esteja em xeque, paradoxalmente, a dinâmica de financiamento e estruturação do campo da saúde alimenta cada vez mais uma engrenagem que conduz à geração de novas demandas, crescente e incontrolavelmente insustentáveis.

Recursos de outra ordem precisam, com premência, ser investidos para reverter essa tendência. Ao mesmo tempo, buscar esses recursos parece ser remar contra uma corrente muito mais poderosa. O modelo científico na saúde, apesar das graves contradiçóes que gera, apresenta a força de ser operativo, instrumental, utilitário. Neste contexto, é decisivo rever a relação entre ciência e filosofia. A relação com o conhecimento precisaria ser transformada para dar espaço a outras formas de expressão da realidade humana na estruturação das práticas de saúde (CZERESNIA, 2003). Para além disso, a própria concepção do que é o corpo poderia ser reconstituída através dessa reflexão. O corpo é descrito por diferentes disciplinas científicas, mas uma delas é hegemônica no campo da saúde: a biologia.

A reflexão de Canguilhem sobre as ciências da vida apresenta uma propriedade filosófica radicalmente importante para a perspectiva de transformação destas 
ciências. Ele elabora uma filosofia das ciências da vida mediada por uma filosofia da vida e, ao fazer isso, assume que o caráter de veracidade do conhecimento sobre a vida deve ter como referência a vida em sua realização, a vida como acontecimento. A reflexão de Canguilhem sobre o caráter de veracidade do conhecimento biológico assinala um problema que questiona este conhecimento em sua base e isto aponta para o núcleo de seus desafios mais importantes.

A filosofia de Canguilhem seria uma epistemologia, uma investigação sobre procedimentos de produção do conhecimento científico, uma avaliação da sua racionalidade, uma análise de cientificidade. Seguindo Bachelard, Canguilhem propóe uma epistemologia regional que busca explicitar fundamentos de um setor particular do conhecimento - no caso, as ciências da vida. Canguilhem exerce seu projeto epistemológico através da reflexão sobre a história dessas ciências. $\mathrm{Ou}$ seja, a característica essencial do projeto epistemológico de Canguilhem é a relação intrínseca entre a epistemologia e a história das ciências (MACHADO, 1982).

A ciência é uma produção cultural, um objeto construído. É um conjunto de proposições articuladas sistematicamente, um tipo específico de discurso que tem a pretensão de verdade. É a questão da verdade que determina a originalidade das ciências com relação a outras manifestações culturais. Para Canguilhem, a história das ciências é uma história conceitual porque é a formação dos conceitos que expressa a racionalidade de uma ciência. Para entender a ciência, Canguilhem privilegia a análise da formação dos conceitos (MACHADO, 1982).

Machado (1982) define a filosofia das ciências da vida de Canguilhem em diferenciação a uma filosofia da vida. Segundo ele, a reflexão de Canguilhem não tem a pretensão de elaborar uma filosofia da vida capaz de propor uma "biologia de filósofo", com o objetivo de defender teses filosóficas sobre a vida, a existência, o homem. Ela contém uma reflexão sobre a vida, mas se exerce de forma indireta, mediante a análise da racionalidade das ciências que a constituem como objeto e não anulando a operacionalidade que caracteriza estas ciências (MACHADO, 1982).

Este artigo argumenta que a força da reflexão filosófica que Canguilhem elabora - ao afirmar que valor é uma propriedade irredutível da vida - é maior e necessita ser recuperada. O próprio autor atesta a importância da mediação da filosofia da vida na epistemologia que constrói ao "mostrar como a filosofia pode intervir na formulação de uma problemática histórica, a problemática que visa a 
biologia. [...] a função própria da filosofia é a de complicar a existência do homem, inclusive a existência do historiador das ciências" (CANGUILHEM, 1977, p. 122). Aborda essa particularidade do pensamento de Canguilhem e defende que ele ultrapassa uma epistemologia apenas preocupada com a cientificidade do discurso e apresenta uma questão essencial à transformação não apenas das ciências da vida, mas da relação entre ciência e filosofia.

\section{Normatividade vital}

O conceito de normatividade vital, proposto na tese $O$ normal e o patológico em 1943, é central na obra de Canguilhem. Esse conceito se configura a partir da análise que o filósofo faz da ambiguidade no uso do termo normal. "Normal" designa aquilo que é como deve ser, e o que é mais frequente, ou constitui a média ou módulo de uma característica mensurável. Denota "ao mesmo tempo um fato e um valor atribuído a esse fato por aquele que fala, em virtude de um julgamento de apreciação que ele adota” (CANGUILHEM, 1995, p. 95). Em medicina, por analogia, expressa "ao mesmo tempo o estado habitual dos órgãos e seu estado ideal, já que o restabelecimento desse estado habitual é o objeto usual da terapêutica" (CANGUILHEM, 1995, p. 96). Canguilhem afirma que, na medicina, o sentido de apreciação de um estado, ou seja, o sentido de valoração por um interessado, é irredutível e ligado a uma circunstância vital:

Achamos que a medicina existe como arte da vida porque o vivente humano considera, ele próprio, como patológicos - e devendo portanto serem evitados ou corrigidos - certos estados ou comportamentos que, em relação à polaridade dinâmica da vida, são apreendidos sob forma de valores negativos. Achamos que, desta forma, o vivente humano prolonga, de modo mais ou menos lúcido, um efeito espontâneo, próprio da vida, para lutar contra aquilo que constitui um obstáculo à sua manutenção e a seu desenvolvimento tomado como normas (CANGUILHEM, 1995, p. 96).

Portanto, valor não seria um atributo apenas humano:

[...] o fato de reagir por uma doença a uma lesão, a uma infestação, a uma anarquia funcional, traduz um fato fundamental: é que a vida não é indiferente às condiçôes nas quais ela é possível, que a vida é polaridade e por isso mesmo, posição inconsciente de valor, em resumo que a vida é, de fato, uma atividade normativa. Em filosofia, entende-se por normativo qualquer julgamento que aprecie ou qualifique um fato em relação a uma norma, mas essa forma de julgamento está subordinada, no fundo, àquele que institui as normas. No pleno sentido da palavra, normativo é o que institui as normas. E é neste sentido que propomos falar sobre uma normatividade biológica (CANGUILHEM, 1995; p. 96). 
O vivo apresentaria uma posição inconsciente de valor, ao exercer seu mais básico metabolismo, como as funções de assimilação e excreção. Esta característica é que demarcaria a especificidade das ciências da vida em relação às ciências da natureza - a física e a química. A normatividade vital se apresenta como um dado o qual a ciência da vida não pode desconsiderar ao perseguir seu caráter de veracidade e sua vocação operacional. Este é o grande problema que ressalta na epistemologia de Canguilhem a tensão entre ciência e filosofia.

O texto "O problema da normalidade na história do pensamento biológico" (CANGUILHEM, 1977) explicita a ideia de a questão do valor ser irredutível quando se trata de abordar a condição de autoconservação da vida, a qual se apresenta como acontecimento que impôs uma base de conservação temática no decorrer da constituição histórica da biologia.

A biologia não seria uma ciência como as outras e a história da biologia devia ressen-
tir-se deste fato, na sua problemática e no modo como é escrita. Pois o suposto prin-
cípio de conservação temática na história da biologia talvez não passe da expressão da
submissão, que assume diferentes formas, do biólogo a este dado da vida, verificável
em qualquer ser vivo, que é a autoconservação por auto-regulação (CANGUILHEM,
1977, p. 109).

O ser vivo não pode ser igualado a um objeto da mecânica. Os projetos de equiparar os seres vivos a uma máquina foram insuficientes e, mesmo no pensamento dos defensores mais radicais dessa perspectiva, a análise do autor encontrou contradições nas quais, de alguma forma, o recurso à ideia de normalidade foi necessário (CANGUILHEM, 1977).

O ser vivo seria dotado de uma qualidade incomparável na natureza. Sua condição de preservação por meio de transformaçōes adaptativas se realiza mediante alguma espécie de "discernimento". Não haveria qualquer possibilidade de explicar o ser vivo prescindindo da noção de valor. Canguilhem utiliza esse argumento para dialogar com a questão formulada por Schroedinger (18871961) em O que é vida? (1997). Este distingue a vida como um comportamento da matéria cuja base é a conservação de uma ordem pré-existente e a denomina neguentropia, por contrariar o princípio da entropia. Canguilhem sustenta:

Os sistemas vivos abertos, em estado de não-equilibrio, mantém a sua organização simultaneamente em virtude de sua abertura ao exterior e apesar da sua abertura. Seja qual for o nome que se lhe atribua, neguentropia, informação ou improbabilidade do sistema, a organização exprime a qualidade de uma certa quantidade física. Isto basta para distinguir a biologia da física, ainda que a primeira pareça ter ligado o seu 
próprio destino ao da segunda. O biólogo não pode deixar de perseverar na utilização do conceito de normalidade (CANGUILHEM, 1977, p. 120).

Propor que a noção de normalidade é imprescindível na história da biologia não implica reconhecer que esta pôde efetivamente ser incluída no seu escopo.

Não terá havido confusão entre os diferentes níveis de compreensão dos objetos da biologia, quando investigamos e pusemos em evidência uma normalidade distintiva desses objetos? [...] foi pela miniaturização crescente dos seus objetos, bactéria, gene, enzima, que os biólogos descobriram, enfim, em que consiste a vida. Ora, as análises precedentes não terão confundido o nível dos fenômenos conhecidos e vividos e o nível dos fenômenos explicados? A normalidade aparece como uma propriedade dos organismos mas desaparece ao nível dos elementos da organização (CANGUILHEM, 1977, p. 121).

Canguilhem, ao pensar a biologia tendo como referência uma filosofia da vida, inscreve como problema para a biologia a constatação de a vida ter a propriedade de criar normas para perseverar. O que seria a característica peculiar à vida desde a mais elementar de realizar alguma espécie de discriminação entre o que lhe é favorável ou desfavorável? A físico-química não explicou esse atributo irredutível à condição de ser vivo.

Pensar a vida fora de uma explicação possível no âmbito das ciências da natureza é uma questão controversa. Canguilhem tem claro que a biologia opera uma redução ao se ancorar na físico-química para explicar a vida. Esta redução, em que a biologia se torna satélite das chamadas ciências naturais, segundo ele, desvaloriza o objeto biológico em sua especificidade. Ao mesmo tempo, uma biologia que busca sua autonomia sempre arrisca a qualificação de vitalismo. A vida não está plena na ciência biológica e a reflexão filosófica apresenta questôes cuja consequência é, do ponto de vista da ciência, uma posição que pode ser acusada de vitalismo.

É no contexto da polêmica sobre um suposto vitalismo que Canguilhem distingue sua filosofia da biologia de uma biologia de filósofo:

Pouco importa ser ou não tido como vitalista ou pecha semelhante que se queira atribuir com esse adjetivo. A rigor, o termo vitalista só deveria servir para designar uma teoria biológica, ou uma filosofia do biólogo, se tal empreendimento tem um sentido para ele, e não uma filosofia da biologia, único empreendimento possível para um filósofo, porém não confundido com uma biologia de filósofo, que seria um projeto monstruoso (CANGUILHEM, 1977, p. 1).

Canguilhem explicita seus argumentos contra a biologia dos vitalistas ser considerada aberração ou esterilidade. Se não há uma chave vitalista para os problemas colocados pela vida à inteligência, não se deve por isso renunciar 
à formação de conceitos para procurar alguma chave perdida. Diante dos problemas que a vida apresenta para o biólogo, a convicção vitalista não gera, pelo contrário, preguiça ou idiotice (CANGUILHEM, 1977, p. 1). Canguilhem não professa uma teoria biológica vitalista, mas sustenta a vitalidade e a fecundidade do vitalismo frente a questôes que a vida e a filosofia da vida irretorquivelmente apresentam para a biologia. Ele não afirma haver uma força vital transcendente, mas reconhece a insuficiência da perspectiva biológica mecanicista e a necessidade de buscar superá-la. Há motivos para a permanência da oscilação entre mecanicismo e vitalismo na história da biologia e a continuidade dessa flutuação está relacionada a uma busca de sentido das relações entre a vida e a ciência (CANGUILHEM, 1992; PUTTIN; PEREIRA JR, 2007).

A biologia não resolveu o que ele assinalou como uma capacidade de escolha anterior ao que o homem discrimina como sua própria possibilidade de pensar; uma condição que emerge na vida mais elementar, da qual o homem é um prolongamento. Haveria, na natureza da vida, algo irredutível a qualquer matemática. Canguilhem não formulou uma biologia de filósofo, mas apresentou um problema essencial para qualquer biólogo interessado em superar os desafios mais contundentes do seu campo de investigação.

Este desafio está presente na discussão sobre as relações entre cérebro e pensamento. Grandes avanços da neurociência apresentariam a possibilidade de desvendar o cérebro e o pensamento como um computador? A reflexão de Canguilhem defende que não e isso não corresponderia apenas a um estágio do conhecimento. Em conferência proferida na década de 1980, o autor reafirma sua posição de o valor ser um atributo fundamental do vivo e estar na origem do pensamento humano.

\section{Cérebro e pensamento}

Para Canguilhem, foi no século XIX que surgiu a primeira teoria que identifica o cérebro como órgão do pensamento humano. O combate entre positivismo e espiritualismo teve como uma forma de expressão a teoria das localizações cerebrais formulada por Gall em 1810. Teria sido esse o momento do surgimento de uma ciência do cérebro (CANGUILHEM, 2006). Poderia a ação do cérebro, como sistema fisiológico-psicológico, produzir fatos intelectuais e morais ou mesmo explicar o mecanismo do pensamento? 
O projeto de encontrar uma correspondência anatômica entre cérebro e mente não pôde ser alcançado. Freud, que inicialmente buscou uma correspondência morfofuncional entre psiquismo e cérebro, elaborou uma tópica psíquica reconhecendo que esta não tem nada a ver com anatomia. Freud não encontrou a localização dos processos psíquicos em células nervosas. O cérebro e o pensamento, apesar de estreitamente vinculados, não correspondem um ao outro. Tanto cientistas quanto poetas estabeleceram essa relação e ao mesmo tempo não a encontraram para além de representações ou metáforas (CANGUILHEM, 2006).

Os fenômenos psicológicos diriam respeito a uma ciência do cérebro ou ao homem por inteiro? Essa questão citada por Canguilhem está na raiz da sua própria reflexão. $\mathrm{O}$ homem pode ser compreendido como máquina ou precisa ser inscrito em uma compreensão da vida como propriedade peculiar de realizar uma posição inconsciente de valor? $\mathrm{O}$ pensamento seria aquilo que um computador realiza quando opera um cálculo, um raciocínio, ou seria impossível separar pensamento da vontade humana que movimenta a invenção e elaboração de máquinas? Não haveria alguma ligação entre vontade, atributo claramente reconhecido como característica humana, e toda sorte de condutas animais orientadas à busca de uma satisfação vital?

Para Canguilhem, a representação construída entre pensamento, cérebro e computador é decorrente de uma estratégia teórica característica da ciência atual: "a partir de observações e de experiências conduzidas em determinado campo da realidade, constrói-se um modelo, e, a partir desse modelo, continua-se a refinar o conhecimento como se estivéssemos lidando com a própria realidade" (CANGUILHEM, 2006, p. 193).

Canguilhem considera impossível equacionar o cérebro como máquina eletrônica (computador) ou como máquina química. Para elucidar o que é o pensamento, não se pode prescindir da ideia de valor, desejo, vontade. Citando Pascal, o autor pergunta: "Mas o que chamamos "pensar" quando se trata desse poder do ser vivo que Pascal chamou de vontade e cuja capacidade de simulação ele nega à máquina?” (CANGUILHEM, 2006, p. 199).

Essa questão diz respeito ao que Varela (1946-2001) apontou como problema ainda em aberto, ao comentar, dez anos depois, a conferência de Canguilhem. Nesse período, segundo Varela, a ciência da cognição alcançou resolver teoricamente a condição de o pensamento humano ser um nível de organização 
superior de processos cognitivos inferiores. O pensamento humano seria uma emergência passível de ser simulada a partir destes processos cognitivos mais simples. A ligação entre pensamento e propriedades cognitivas mais gerais não seria utópica, mas estaria na base de um programa construtivo (VARELA, 1991).

Ao afirmar isso, Varela não admite estar antevendo o triunfo de algum novo mecanismo mediante a explicação de propriedades emergentes como concepção central. Algo fundamental da reflexão de Canguilhem permanece e se tornaria o centro mais importante de controvérsias futuras. Segundo Varela, processos cognitivos, de onde resulta a cognição mais elevada, são não-reflexivos por definição e o sujeito emergente não se separa das ocorrências que apoiam sua constituição. Haveria, portanto uma ambiguidade fundamental entre um mecanismo que explicaria a emergência do pensamento a partir de processos cognitivos mais simples e a experiência do ponto de vista do mundo vivido. $\mathrm{O}$ ponto central não resolvido seria equacionar a circularidade entre a exterioridade de um mecanismo e a interioridade da experiência vivida (VARELA, 1991).

Este mesmo aspecto é também ressaltado por Damásio, vinte anos após a conferência de Canguilhem, ao abordar o mistério da consciência, o qual ele reconhece ser aquém do mistério da mente. Segundo Damásio, conquistas da neurociência poderiam conduzir à construção de artefatos com mecanismos formais do que se conhece sobre a consciência, mas não seria possível criar um artefato com algo que se assemelhasse à consciência humana na perspectiva da sua interioridade (DAMÁSIO, 2000).

A permanência dessa questão atesta a atualidade da perspectiva de Canguilhem. Os conceitos de cognição e informação foram elaborados segundo modelos que não relacionaram cognição a valor, vontade ou desejo. Canguilhem deixa claro, não apenas na conferência sobre cérebro e pensamento, como em toda sua obra, que não compartilha a ideia de que qualquer processo cognitivo em um ser vivo possa ser equiparado a um mecanismo. Canguilhem, ao afirmar que a história do pensamento biológico não pôde prescindir da questão do valor, propõe para toda e qualquer definição de vida um problema identificado na emergência do humano. Canguilhem reconhece nas funções metabólicas mais básicas, como as de assimilação e excreção, essa circularidade entre a exterioridade de um mecanismo e a interioridade da experiência do vivo. Processos cognitivos nos seres vivos conteriam alguma espécie de subjetividade. 
O homem exerceria a experiência de interioridade como prolongamento de uma condição básica à possibilidade de uma estrutura física perseverar à revelia do principio da entropia. A condição de emergência do humano a partir de estruturas mais simples seria uma possibilidade inscrita na condição de ser vivo.

Voltando a $O$ normal e o patológico, Canguilhem considera a arte humana da cura o prolongamento de um efeito espontâneo e próprio da vida: o de lutar contra aquilo que constitui obstáculo à sua manutenção. $\mathrm{O}$ homem prolonga com a técnica algo que está inscrito na condição vital:

\begin{abstract}
Não emprestamos às normas vitais um conteúdo humano, mas gostaríamos de saber como é que a normatividade essencial à consciência humana se explicaria se, de certo modo, já não estivesse em germe na vida. Gostaríamos de saber como é que uma necessidade humana de terapêutica teria dado origem a uma medicina cada vez mais clarividente em relação às condições da doença, se a luta da vida contra os inúmeros perigos que a ameaçam não fosse uma necessidade vital permanente e essencial. Do ponto de vista sociológico, é possível mostrar que a terapêutica foi, primeiro, uma atividade religiosa, mágica, mas não se deve absolutamente concluir daí que a necessidade terapêutica não seja uma necessidade vital, necessidade que - mesmo nos seres vivos bem inferiores aos vertebrados quanto à organização - provoca reaçôes de valor hedônico ou comportamentos de auto-cura e de auto-regeneração (CANGUILHEM, 1995, p. 97)
\end{abstract}

\title{
A definição de vida
}

As dificuldades que permanecem na definição de vida reiteram a propriedade da reflexão filosófica de Canguilhem. Por que as definiçõoes sobre vida são tão evasivas? Esta questão é proposta por Tsokolov (2009), cuja análise auxilia a situar os problemas relativos ao grande desafio de encontrar uma definição de vida que seja curta, universal e igualmente aceita como definição padrão entre as ciências.

$\mathrm{O}$ autor ressalta a inexistência de uma definição de vida consensual aos diferentes campos de conhecimento, os quais se expandiram com crescente perda de linguagem em comum. Ele assinala três dificuldades epistemológicas importantes para a definição de vida: a definição por termos que são por sua vez mal definidos; a definição por uma combinação de descriçōes; a definição por tentativa de arbitrar um sistema mínimo a ser caracterizado como vida.

Não há um consenso entre especialistas ou cientistas interdisciplinares sobre o significado de termos como informação, complexidade, metabolismo, ordem, autoorganização, autoconservação, etc. O problema não é apenas a dificuldade de utilizar estes termos através de linguagens de campos científicos distintos, mas 
a falta de clareza da definição desses termos neles mesmos (TSOKOLOV, 2009).

Por exemplo, o termo informação é utilizado indistintamente em interpretaçōes que conduzem a diferentes definiçooses de vida: tanto as mais estreitas que reduzem bioinformação ao contexto da genética (código genético, programa genético, projeto do DNA); como mais amplas, que a designam no contexto do sistema vivo como um todo em redes de controle, circuitos e sinais. Nas teorias da ciência da computação e da matemática, a noção de informação é a de dados sem significação, algoritmos, dispositivos de controle. Quando utilizado para denominar processos vitais, o emprego do termo é, na maior parte das vezes, metafórico, como no caso da designação de "programas inteligentes" ou de “inteligência artificial” (TSOKOLOV, 2009).

Os modelos que propõem informação como componente não incluem, como visto anteriormente, a dimensão do valor. $\mathrm{O}$ uso metafórico do termo remete ao problema central da obra de Canguilhem, pois evidencia como as tentativas de definição do que é vida não alcançam prescindir dessa dimensão. Esse mesmo problema se apresenta quando definições de vida são propostas mediante a descrição dos seus atributos como metabolismo, crescimento, reprodução, adaptação, hereditariedade, evolução, complexidade, reatividade, movimento, irritabilidade, etc. Qual seria o atributo primordial que viabilizaria secundariamente a emergência dos outros? Ou seja, "o que especificamente ocorre nos sistemas vivos que lhes permite crescer, metabolizar, reproduzir, evoluir, aumentar a complexidade e processar informação?” (TSOKOLOV, 2009, p. 408).

De acordo com Schroedinguer (1997), essa propriedade seria a de manter ordem à revelia do princípio da entropia. Porém, como argumentou Canguilhem, este caráter essencial não seria antes uma condição normativa? Vida como posição inconsciente de valor poderia ser esse atributo?

$\mathrm{O}$ artigo de Tsokolov evidencia a dificuldade de se encontrar uma definição de vida que seja ao mesmo tempo curta e extensiva a todos os atributos da vida desde aqueles que se articulam a sistemas físico-químicos, aos que estão compreendidos por sistemas ecológicos, mentais e sociais. Essa dificuldade está também ligada a de se buscar uma definição de vida com parâmetros passiveis de tratamento quantitativo (TSOKOLOV, 2009).

A definição de vida como posição inconsciente de valor não se coaduna com a perspectiva quantitativa das ciências da natureza. $\mathrm{O}$ que poderia ser valor como 
definição do que é vida? Constituintes metabólicos poderiam apresentar uma dimensão que se considera inaugurada pela vida humana?

Os sentidos de força vital não são suficientes para dar conta deste problema que permanece na discussão contemporânea sobre a definição de vida. $\mathrm{O}$ chamado "vitalismo" de Canguilhem traz como interrogação algo muito além de uma elaboração que transcende a natureza. Não se trata de uma questão fora da ciência, mas algo que precisa ser enfrentado no contexto da relação entre ciência e filosofia. Essa questão se refere a um problema que tangencia o limite de o homem conhecer da forma como a ciência moderna o fez, além de apontar para o cerne da formação dual e da concepção de homem na sociedade ocidental moderna.

\section{Categoria vida e concepção do homem na modernidade}

Foucault (1995) estudou o surgimento do homem moderno. As condições de possibilidade para essa emergência são analisadas em As palavras e as coisas. Este trabalho apresenta reflexões fundamentais para a compreensão da construção da concepção de homem e também para pensarmos hoje sua transformação.

O homem moderno surgiu no ocidente em uma condição construída com base na experiência do mundo clássico. As categorias vida, trabalho e linguagem surgiram a partir do século XVIII, período considerado pelo autor limiar da modernidade, e viabilizaram um projeto de conhecimento (FOUCAULT, 1995).

A categoria vida surge articulada às de trabalho e linguagem. Surgiram em uma mesma base epistêmica no sentido da sua origem de perspectiva dualista. Porém, do ponto de vista da construção epistemológica do homem, houve uma profunda cisão em que o corpo foi concebido como organismo enquanto linguagem e trabalho foram compreendidos de modo imaterial e em estatuto de cientificidade diferenciado.

Os objetos das ciências humanas constituíram-se para além da configuração da categoria vida. Isso traz problemas não apenas para a compreensão do homem, mas aparece como questão no interior da própria biologia, no conflito que opôs mecanicismo e vitalismo. Se o vitalismo foi uma condição de possibilidade para o surgimento da biologia (JACOB, 1983), foi do seu expurgo que ela se constituiu como ciência. As ciências da mente e a psicanálise estabeleceram-se na sobra, em algo que não entrou na formalização da estrutura orgânica (BIRMAN, 2007). As ciências humanas produziram um homem em uma divisão ainda não 
equacionada. Mudanças na concepção de homem devem passar pela redefinição e

pelo encontro de uma ligação entre as categorias que o fundaram na modernidade.

Considerar uma ligação entre as categorias que definem o homem não significa "naturalizá-lo" em uma biologia que o reduz, mas questionar a condição reduzida da biologia e buscar ampliar a categoria vida. Este alargamento não significa confundir domínios diferenciados da experiência humana, mas qualificar esses diferentes domínios como decorrentes de uma mesma origem. O humano é uma decorrência evolutiva da condição de ser vivo.

O homem é um ser vivo cuja existência é constituída de desejo, necessidade; e pensamento, linguagem. Vida, desejo e pensamento definem o homem como ser vivo. O homem apresenta desejo e pensamento porque é ser vivo. Existiria a condição de se transformar a maneira de conhecer o homem ao se integrar o conceito de normatividade vital à biologia? A relação entre vida, trabalho e linguagem poderia ser estruturada em uma base biológica cuja origem seria o conceito de normatividade vital.

\section{Normatividade Vital e Vontade de Poder}

O conceito de normatividade vital é filiado ao de vontade de poder, de Nietzsche (1844-1900). O pensamento de Nietzsche, em ligação com a filosofia grega présocrática, está próximo da elaboração de Canguilhem. Nietzsche compartilha a ideia de que a physis apresenta elementos fundamentais para a reorientação do pensamento ocidental e da concepção do homem moderno. Não é objetivo deste artigo aprofundar este tema, mas apontar a referência filosófica que orienta a perspectiva de Canguilhem.

A filosofia pré-socrática propõe outra compreensão de natureza, não dissociada do humano. O pensamento biológico de Nietzsche é afinado com essa compreensão. O conceito de normatividade vital encontra o de vontade de poder como uma potência que realiza a própria vida orgânica.

O conceito vitorioso, "força", com o qual nossos físicos criaram Deus e o mundo, necessita ainda ser completado: há de ser-lhe atribuído um mundo interno que designo como "vontade de poder", isto é, como insaciável ansiar por mostrar poder; ou emprego, exercício de poder, pulsão criadora etc. Os físicos não se libertarão, a partir dos seus princípios, do "efeito à distância": tampouco de uma força de repulsão (ou de atração). Isso não ajuda em nada: há de conceberem-se todos os movimentos, todas as "manifestaçôes", todas as "leis" somente como sintomas de um acontecimento interno, e por 
fim servir-se da analogia do homem. No animal, é possível derivar da vontade de poder todas as suas pulsões; da mesma maneira, todas as funções da vida orgânica podem ser derivadas dessa única fonte (NIETZSCHE, 2008, p. 319-320 [619]).

Os aforismos de Nietzsche que se referem à dimensão orgânica podem ser interpretados como uma intuição capaz de vislumbrar o corpo numa perspectiva que rompe o dualismo. A presença do pensamento humano é decorrente de uma realidade vital que já ocorre em uma ameba.

Todo pensar, julgar, perceber, como comparar, tem como pressuposto um "equiparar", ou, antes, um "tornar igual". O tornar igual é a mesma coisa que a incorporação de matéria apropriada na ameba (NIETZSCHE, 2008, p. 266 [501]).

[...] Não há dúvida de que todas as percepções dos sentidos estão totalmente penetradas de juízos de valor (útil e prejudicial - consequentemente, agradável e desagradável) (NIETZSCHE, 2008, p. 267 [505]).

Considerar que valor é anterior ao homem é afirmar a realidade biológica do pensamento, da qual o humano é um desdobramento que realiza o sentido da própria experiência vital. A categoria vida foi destituída de interioridade pela biologia moderna. Porém, a subjetividade humana se realizaria numa experiência cuja origem é uma subjetividade de outra ordem que materializaria a própria vida orgânica. A objetividade seria aquilo cuja presença aparece independentemente de escolhas porque estas estariam numa ordem anterior e mais elementar do que a consciência humana.

Que as coisas tenham uma constituição em si, completamente abstraída da interpretação e da subjetividade, é uma hipótese inteiramente ociosa: seria pressupor que o interpretar e o ser sujeito não seriam essenciais, que uma coisa desligada de todas as relações ainda seria coisa.

Pelo contrário: o aparente caráter objetivo das coisas ele não poderia decorrer simplesmente de uma diferença de grau no interior do subjetivo? - de modo, por exemplo, que o que muda lentamente se apresentasse para nós como durando "objetivamente", como sendo, como "em si"?

- de modo que o objetivo fosse apenas uma falsa espécie de conceito e uma falsa oposição no interior do subjetivo? (NIETZSCHE, 2008, p. 292 [560]).

Vontade de poder é a força que faz a vida evoluir sem isso significar obrigatoriamente elevação ou progresso. A vida crescer e se diversificar não é apenas condição do acaso e de seleção natural do ambiente.

- A influência das "circunstâncias externas" é supervalorizada em Darwin até a insensatez; o essencial no processo de vida é justamente o poder [Gewalt $]$ imensamente 
configurador, criador de formas a partir de dentro, o qual explora, despoja as "circunstâncias externas"...

Que as novas formas, configuradas a partir de dentro, não são formadas em relação a um fim; mas que, na luta das partes, uma nova forma não permanecerá por muito tempo sem uma relação com uma utilidade parcial, e depois, de acordo com o uso, conformar-se-á de forma cada vez mais acabada (NIETZSCHE, 2008, p. 329 [647]).

A vida não é adaptação de condições internas a externas, mas sim vontade de poder, a qual, a partir de dentro, submete-se a si e incorpora cada vez mais "exterior" (NIETZSCHE, 2008, p. 344 [681]).

Canguilhem elabora o conceito de normatividade vital em relação ao problema da autoconservação da vida, mas também em ligação com as mudanças que fazem parte dela. Em Nietzsche, conservação é consequente à vazão que o vivo dá à sua força.

Antes de postular a pulsão de conservação como pulsão cardeal de um ser [Wesen] orgânico, os fisiólogos deveriam pensar bem. Antes de tudo, algo vivo quer dar vazão à sua força: a "conservação" é somente uma das consequências disso. - Precaução com os princípios teleológicos supérfluos! E a isso pertence todo o conceito de "pulsão de conservação" (NIETZSCHE, 2008, p. 344 [681]).

O conceito vontade de poder tem vigor para inscrever a vida na condição de conservação e transformaçãa. A vida é uma posição inconsciente de valor que determina sua condição orgânica e espiritual. O caráter dual é desdobramento de uma unidade cuja origem é valor.

A vontade de poder só pode externar-se em resistências; ela procura, portanto, por aquilo que lhe resiste - essa é a tendência original do protoplasma quando estende pseudópodes e tateia em torno de si. A apropriação e a incorporação são, antes de tudo, um querer-dominar, um formar, configurar e transfigurar, até que finalmente o dominado tenha passado inteiramente para o poder do agressor e o tenha aumentado. - Se essa incorporação não vingar, então provavelmente se arruína a configuração; e a dualidade aparece como consequência da vontade de poder: para não deixar perder-se o que foi dominado, a vontade de poder desvencilha-se em duas vontades (em certas circunstâncias, sem abandonar completamente a sua ligação uma com a outra). "Fome" é somente uma adaptação mais estreita, depois que a pulsão fundamental por poder ganhou uma constituição mais espiritual (NIETZSCHE, 2008, p. 331 [656]).

\section{O corpo não está separado do pensamento, ao contrário ele é pensamento e se} constitui como resultado da vontade de poder.

O corpo humano, no qual tanto o passado mais longínquo quanto o mais próximo de todo devir orgânico torna-se de novo vivo e corporal, por meio do qual sobre o qual e 
A vida se produz a partir de uma condição irredutível de valor. "O ponto de vista do "valor" é o ponto de vista das condiçõos de conservação e incremento com referência à complexa configuração da relativa duração da vida no interior do devir" (NIETZSCHE, 2008, p. 360 [715]). Essa afirmação de Nietzsche está na origem do conceito de normatividade vital. Quando Canguilhem apresenta sua epistemologia, ele confronta o pensamento científico com a filosofia da vida que assume a necessidade de uma transformação radical da relação do homem com o conhecimento. Vida como valor não se submete à vontade de domínio do homem, pois se trata de algo mais potente que ele. Talvez por isso haja tanta dificuldade em realizar essa mudança na definição do que é vida.

\section{Repensar a relação entre ciência e filosofia}

Para finalizar, apontam-se aspectos da discussão a ser desenvolvida a partir do resgate do conceito de normatividade vital. O pensamento de Canguilhem no início do século XXI pode suscitar uma forma de interpretar o problema da normalidade na biologia articulado ao desafio numa região epistemológica que ele não abordou. Canguilhem afirmou que valor é uma propriedade biológica irredutível, mas isso não significa que seja a propriedade passível de configurar "autonomia" para a biologia.

Valor não é algo fora da natureza, mas ao contrário, a própria natureza da vida. Se a vida é parte da natureza, valor seria uma condição física propriamente biológica. A questão a ser acrescentada é se, enquanto ser vivo, o homem poderia estar na natureza sem ter a dimensão do valor mediando todas as possíveis descrições que faz acerca dela. $\mathrm{O}$ valor seria base de toda experiência e descrição do homem no universo, na medida em que seu próprio corpo teria essa dimensão constituinte fundamental.

A questão do valor apresenta-se também na física, em decorrência da inexistência de uma formulação matemática para a passagem do mundo quântico ao mundo clássico. Existe uma interpretação possível para esse problema em aberto na física, articulada ao problema da normalidade na biologia. A inexistência de uma formulação matemática para a passagem do nível quântico ao clássico não poderia ser decorrente da circunscrição de um limite biológico na condição humana de 
perscrutar o universo? Esse limite biológico não poderia ser justamente a condição normativa intrínseca à estrutura viva? (CZERESNIA, 2010).

Há dificuldades para dar sentido adequado a questões em aberto em saberes que apresentam linguagens díspares e afastadas. Hipóteses formuladas por físicos renomados podem parecer extremamente especulativas e pouco consistentes quando se referem à vida. Por sua vez, filósofos não são físicos nem biólogos, e existe uma dificuldade enorme de diálogo quando os pensadores estão preocupados com o rigor dos conceitos que utilizam nos seus campos de origem.

O conceito de normatividade vital apresenta a possibilidade de transformação da relação entre ciência e filosofia ao afirmar valor como a condição do ser biológico. Uma ontologia da vida seria anterior e fundamental para o homem compreender o limite do seu conhecimento sobre o universo. As representações construídas pelo conhecimento científico teriam essa ontologia como base de interpretação. Vida como posição inconsciente de valor afirma a materialidade do pensamento, da qual o humano seria um desdobramento evolutivo. Isso atestaria ser a vida biologicamente filosófica.

Essa afirmação não é passível de confirmação científica pelos critérios usuais, mas pode ser validada mediante sua capacidade de favorecer um modo compreensivo de articular problemas não resolvidos em diferentes saberes. Dessa forma, o conceito de normatividade vital, proposto por Canguilhem, pode ser, para além da epistemologia das ciências da vida, chave para importantes e necessárias mudanças na cosmologia da sociedade contemporânea.

\section{Referências}

BIRMAN, J. A biopolítica na genealogia da psicanálise: da salvação à cura. História, Ciências, Saúde - Manguinhos. Rio de Janeiro, v. 14, n. 2, p. 529-548, abr./jun. 2007.

CANGUILHEM, G. O cérebro e o pensamento. Natureza Humana. São Paulo, v. 8, n. 1, p. 183-210, jan./jun. 2006.

CANGUILHEM, G. O problema da normalidade na história do pensamento biológico. In: . Ideologia e racionalidade nas ciências da vida. Lisboa: Ediçōes 70, 1977.

CANGUILHEM, G. O normal e o patológico. Rio de Janeiro: Forense-Universitária, 1995. CANGUILHEM, G. Aspects du vitalisme. In: . La connaissance de la vie. Paris: J. Vrin, 1992. p. 105-128.

CANGUILHEM, G La formation du concept de réflexe aux XVII et XVIII siècles. Paris: Presses Universitaries de France, 1977. 
CZERESNIA, D. O conceito de saúde e a diferença entre prevenção e promoção In: CZERESNIA, D.; FREITAS, C.M. (Org.). Promoção da saúde: conceitos, reflexões, tendências. Rio de Janeiro: Fiocruz, 2003. p. 39-53.

CZERESNIA, D. Normatividade vital e dualidade corpo mente. Psicologia em Estudo, no prelo. DAMÁSIO, A. O mistério da consciência: do corpo e das emoções ao conhecimento de si. São Paulo: Companhia das Letras, 2000.

FOUCAULT M. As palavras e as coisas: uma arqueologia das ciências humanas. São Paulo: Martins Fontes, 1995.

JACOB, F. A lógica da vida: uma história da hereditariedade. Rio de Janeiro: Graal, 1983.

MACHADO, R. Ciência e saber: a trajetória da arqueologia de Foucault. Rio de Janeiro: Graal, 1982.

NIETZSCHE, F. A vontade de poder. Rio de Janeiro: Contraponto, 2008.

PUTTINI, R. F.; PEREIRA JÚNIOR, A. Além do mecanicismo e do vitalismo: a "normatividade da vida" em Georges Canguilhem. Physis: Revista de Saúde Coletiva. Rio de Janeiro, v. 17, n. 3, p. 451-464, 2007.

SCHROEDINGER, E. O que é a vida? São Paulo: Unesp, 1997.

TSOKOLOV, S. A. Why is the definition of life so elusive? Epistemological considerations. Astrobiology, v. 9, n. 4, p. 401-412, 2009.

VARELA, F.J. Le cerveau et la pensée. In: MICHEL, A. (Org.). Georges Canguilhem, philosophe, historien des sciences: Actes du colloque, 6-7-8 décembre, Biblioteque du Collège Internationale de philosophie, 1990.

\section{Agradecimentos}

Agradeço ao Prof: Emmanuel Carneiro Leão a orientação e oportunidade de rica interlocução. Ao Prof: Gilvan Fogel, as aulas e discussões fecundas. Aos colegas do Instituto de Filosofia e Ciências Sociais, em especial a Izabela Bocayuva e Rômulo Pizzolante, os debates acalorados e importantes sugestôes. A Cecília Maria Fiorotti e Mônica Clemente, a leitura e sugestões valiosas. 


\section{Canguilhem and philosophy in the life sciences} This paper examines the relevance of Canguilhem's thought regarding changes in the life sciences, and the relationship between science and philosophy. It shows that the concept of vital normality, and its focus on value as essential trait of life, reveals, in biology, a basic problem of knowledge. A nuclear concept in Canguilhem's thought, present in all of his work - as made clear, in 1980, by his contribution at the Conference on the Brain and Thought - it's still actual in present-day discussion of unanswered questions in the neurosciences and in definitions of life. No brief, universal definition of life is generally accepted, in the sciences, as standard definition. To define life as unconscious position of value is not in accordance with the quantitative perspective of natural science. What is value as definition of life ? Can metabolic components present a dimension shown to be inaugurated by human life? Such questions may only be equations after indispensable changes in the concepts of man and his relationship with knowledge. In the final part, affinity is established between Canguilhem's concept of vital normality and the will to power of Nietzsche. The concept of vital normality links to the will to power as organic life-creating force. To postulate value as previous to man is to uphold the biological reality of thought, from which develops humanity, fulfilling with meaning the experience of life.

> Key words: Canguilhem, life sciences, philosophy. 